\title{
ORGANIZACIÓN Y ACCIÓN COLECTIVA EN LAS GRANDES CIUDADES LATINOAMERICANAS
}

\author{
Francisco Javier Garrido García*
}

Las recientes y radicales transformaciones de la distribución de la población en el territorio de los países de América Latina -migraciones rurales y urbanización espectacular, concentración de población en la ciudad capital, etc.- han afectado a todos los órdenes de la vida social, política y cultural, atrayendo la atención de los investigadores sociales. Uno de los aspectos especialmente preocupantes y complejos de la nueva situación es el referido a la integración social, organización y acción colectiva de los residentes en los barrios urbanos de las grandes metrópolis.

En este área temática, algunas cuestiones que despiertan un interés general tanto desde el punto de vista teórico como político se refieren a los objetivos, sentidos y potencialidades de la organización y acción colectiva. En torno a tales asuntos se desarrollará este artículo. Pero, ante la diversidad de perspectivas y aproximaciones teóricas aplicadas, se hace preciso comenzar explicitando los postulados teóricos que guían nuestro análisis. A ello dedicaremos la primera parte, mientras que en la segunda se sintetizan los resultados correspondientes al estudio de casos que se realizó en Caracas y Bogotá, dos metrópolis de sendos países latinoamericanos'.

\section{POSTULADOS DEL ANÁLISIS}

\section{Diversas expresiones de la acción}

En los estudios sobre acción colectiva y movimientos sociales urbanos, la mayoría de los investigadores centra su atención en acontecimientos notorios de movilizaciones y en las organizaciones formalmente estructuradas que pretenden dirigirlos. Sin embargo, las acciones manifiestas de los actores (movilizaciones, actos de protesta, propuestas políticas, etc.) deben ser concebidas como un "momento" -producto y reanudación, al mismo tiempo- del proceso de la acción colectiva. Si bien cada actuación concreta tiene sus propios objetivos, medios, efectos y significados, sólo se pueden comprender correctamente dentro del proceso global en el que se integran.

Partimos de la evidencia de que la gama de actividades a realizar en pro de objetivos determinados es amplia y diversa. La lucha por la dotación de servicios de un barrio se puede expresar, por ejemplo, en la negociación (independiente $\mathrm{y} / \mathrm{o}$ partidista) con las autoridades, en movilizaciones sociales más o menos pacíficas, o en la autogestión de los vecinos. Pero, lo más significativo para el análisis es que un mismo actor puede alternar o, incluso, desarrollar de forma simultánea actuaciones concretas diversas y aparentemente contradictorias en su sentido, que sólo será comprensible, en consecuencia, si se observa desde la totalidad del proceso de la acción colectiva.

De esta argumentación se deriva otro principio del análisis: las manifestaciones concretas de la acción colectiva se han de comprender e interpretar en el marco de las relaciones entre los actores afectados. Son ellos quienes definen los objetivos y modos en que se desarrolla la acción y quienes reformulan constantemente sus sentidos implícitos. El interés analítico, por tanto, está más en las relaciones entre los actores intervinientes, en la conducta subyacente a su manifestación pública y en los valores puestos en juego, que en las actuaciones específicas (por muy espectaculares que sean) aisladas del proceso global de construcción de la acción colectiva.

Estos postulados nos llevan a establecer una distinción importante entre movilización y acción colectiva. El desarrollo de la acción colectiva se compone de diversos momentos, unos son de pasividad, otros de pequeñas y, en apariencia, insignificantes acciones realizadas en la vida cotidiana y, por último y más bien de manera excepcional, de actos públicos más o menos espectaculares. La acción colectiva no se reduce, por tanto, a la expresión movilizadora de los actores, ni a la representación pública de la dinámica de interacción en la que se sostienen, ni tampoco al proyecto explícito que proponen. Tan relevante como estos aspectos son las redes asociativas sumergidas en la

* Profesor Ayudante en el Dpto. de Ecología Humana, Población de la Universidad Complutense de Madrid.

1. La selección de las fuentes de información, la aplicación de las técnicas y el desarrollo de todo el trabajo empírico de la investigación son fruto de una labor conjunta y coordinada del equipo que ejecutó desde Agosto de 1989 a Mayo de 1993 el proyecto "Tejido social, pautas asociativas y división socioespacial de la ciudad. Estudio comparativo en Bogotá y Caracas". Los datos y la información que utilizamos se extraen básicamente de ese trabajo común, pero han sido combinados, analizados y actualizados en función del marco teórico que proponemos. 
vida cotidiana, que de forma directa y personal generan pequeñas actividades y cambios poco espectaculares, y que sólo en casos puntuales o sólo parcialmente se identifica con los actos más públicos y manifiestos.

Por otro lado, el sentido de cada acción concreta, cualquiera que sea su repercusión pública, no se refiere únicamente a los intereses y objetivos que declara. Las investigaciones sobre los movimientos sociales contemporáneos han puesto de manifiesto que son tan importantes los objetivos como el modo en que se producen las acciones. Así, el funcionamiento democrático de los actores, la autonomía o dependencia de agentes externos, las categorías sociales de los participantes (por estrato social, género, edad, etnia), se presentan como aspectos de interés analítico tan substancial como los intereses y objetivos hacia los que se dirige la acción.

En definitiva, las actuaciones concretas son polisémicas y polivalentes, no se agotan en sus objetivos explícitos ni en sus efectos directos. La función del investigador consiste en indagar y descubrir cuáles son las dimensiones pertinentes del análisis y cuáles los significados y valores de una acción particular. Y, respecto a estas cuestiones, tanto los objetivos como los modos de conseguirlos se imbrican en la totalidad del proceso de la acción colectiva.

\section{Redes de movimiento y dimensiones de la acción colectiva}

Las apreciaciones anteriores reinciden en la diferencia planteada por Melucci (1989) respecto a los polos de latencia y visibilidad de los movimientos sociales o, en términos de Villasante (1991; 1994), los contenidos latentes y manifiestos y las ondas cortas y largas de la acción. Partiendo de una perspectiva similar, es preciso incorporar una visión de conjunto de la acción colectiva que reconsidere las dimensiones presentes en la acción y los criterios de análisis de sus potencialidades. Entramos así en uno de los puntos más debatidos entre los investigadores: en qué campos de la realidad inciden y qué capacidad de cambio tiene la acción colectiva y los movimientos sociales urbanos.

Para tal fin, vamos a evitar la utilización del concepto "movimiento social", pues estimamos que su acepción más común no da cuenta de forma adecuada de la complejidad de la realidad que intentamos comprender e interpretar. $\mathrm{La}$ complejidad del objeto de estudio que aquí abordamos no encaja con la concepción del movimiento social como un sujeto unificado (consciente de su identidad), dotado de una organización y un proyecto racional de transformación social o política, cuya consecución supone la lucha contra otro u otros sujetos-enemigos definidos. Una simplificación teórica de este tipo no se ajusta a una realidad caracterizada más bien por redes de acción colectiva que se desarrollan como construcciones sociales dinámicas y heterogéneas, activadas a través de grupos interrelacionados en la cotidianeidad.

Incluso los casos reales que pudieran asemejarse al modelo conceptual de movimientos sociales, nacen y se recrean a través de redes de pequeños grupos fragmentados, interconectados y activos en la vida cotidiana; y marcados -más aún cuando se trata de movimientos sociales urbanos- por la "socialidad" que acompaña a la convivencia cotidiana. La acepción habitual de movimiento social no deja claro que se trata de un proceso dinámico que se construye y fundamenta en las redes de grupos informales y asociaciones formales que participan en la acción colectiva. En consecuencia, a falta de otros conceptos que den cuenta de dicho proceso de forma más adecuada, en lugar de usar el término movimientos sociales, recogemos la noción de redes de acción colectiva, que hace referencia a la articulación de numerosas y diversas acciones colectivas y grupos localizados ${ }^{2}$.

Desde esta perspectiva adquieren un papel fundamental las prácticas de la red en la vida cotidiana, que por lo general atienden a lo inmediato y común, elaborando al mismo tiempo medios y fines. En esta acción se reproducen, alteran e innovan cotidianamente las orientaciones que rigen la organización y funcionamiento de la sociedad. Su ámbito de acción es la sociedad civil, en la que se crean y experimentan las normas, identidades y principios de dominación social. La acción colectiva en la vida cotidiana (el polo de latencia, en la terminología de Melucci) cubre todos los aspectos de la vida social, afecta tanto a las dimensiones políticas como a las culturales, y lo hace tanto por los fines que persigue como por las formas en que lo experimenta.

La acción colectiva crece y se nutre de la producción diaria de marcos de significados en los que la red se funda y experimenta cotidianamente (latencia). La manifestación pública del fenómeno y su acción política observable (visibilidad) cumplen, por un lado, la función de mostrar la oposición o adecuación a la lógica de la política institucional y, en algunos casos, señalan que un problema específico está vinculado a la lógica general del sistema y que son posibles modelos sociales alternativos.

Por tanto, y a diferencia de la mayoría de los estudios sobre movimientos sociales, el análisis de la acción colectiva no se puede circunscribir a su manifestación más visible o a los efectos inmediatos que producen en el sistema político. Hay que tomar en consideración sus dimensiones sociales y culturales y, también, las consecuencias que produce a largo plazo en el medio social. Como señala Cohen (1985) refiriéndose a los nuevos movimientos sociales, éstos se plantean temas de identidad personal y social, enfrentan la interpretación social de las normas, las reformulan e inventan y experimentan formas alternativas de relación con el medio. Por ello, las redes de acción colectiva no pueden ser evaluadas únicamente en términos de un paradigma político: "Los contenidos y horizontes de las asociaciones y movimientos no juegan ya sobre el mismo eje que el Estado-Mercado, o público o privado, sino con supersonalidad propia plantean lo comunitario o comunal, la potencia de un tercero en discordia. Es otra forma jurídica (ni pública ni privada), otra forma económica (sin ánimo de lucro), y otra forma cultural (ni liberalismo, ni estatalismo), la que se está planteando" (Villasante, 1991: 46).

2. La idea de red o redes de movimiento se desarrolla en autores como A. Melucci (1985; 1989), Rodríguez Villasante $(1989,1994)$ e I. Scherer-Warren (1993). 
Además, la socialidad (entendida como fuerza subterránea que atraviesa la convivencia, el sentir común, la identificación social de los grupos que comparten un territorio determinado) se encuentra en la base de la acción colectiva, impidiendo reducirla a la racionalidad instrumental o a la lógica de la política. La duplicidad, el secreto, la actitud reservada, que caracterizan a la socialidad, son más tenaces que las adhesiones puntuales a una organización, a una ideología o un proyecto abstracto-racional de cambio.

Concebida, por tanto, como red de acciones colectivas y organizaciones sociales, la realidad a que hace referencia el concepto de movimiento social no podrá ser circunscrita a los límites de un sujeto social que realiza una definición de sentido racional y propone un proyecto. Por su componente afectivo, relacional, fruto de identificaciones múltiples, las redes sobrepasan el marco organizativo y la lógica del interés instrumental y de la política. Se produce así la tensión que señala Melucci entre la necesidad de elaboración racional y de representación pública de un proyecto, por un lado, y la puesta en práctica de una forma directa y personal de las innovaciones de sentido generadas por la red en la vida cotidiana, por otro.

Tal inadecuacion de la representación institucional provoca la fragmentación de los actores en grupos locales que reinventan las formas y objetivos de la acción colectiva y que tienen poco que ver con la dinámica de la política. $\mathrm{La}$ paradoja que dinamiza la acción colectiva consiste en que requiere una representación organizativa que le confiera unidad y eficacia instrumental, pero, como no es posible una representación completa, la acción reaparece con nuevas organizaciones, objetivos y estrategias que generan nuevos conflictos (Melucci, 1989) ${ }^{3}$.

Pero podríamos ir más allá y plantear como hipótesis que dicha tensión proviene fundamentalmente de la ruptura del vector emocional, especialmente cuando se trata de redes de movimiento formadas en base a la territorialidad. Si asumimos que la dimensión afectiva y convivencial atraviesa a las redes y a la acción colectiva formadas en la vida cotidiana, el problema para la red de movimiento deviene cuando se da forma de proyecto claro y racional a los sentidos de la acción que se inventan y experimentan tentativamente en la cotidianeidad, perdiendo así el sentido de socialidad en favor de la representación institucional. Una paradoja dinamizadora y enriquezedora de sentido de los movimientos sociales, pero, al mismo tiempo, talón de aquiles de su eficacia política inmediata.

\section{Potencialidad de la acción colectiva}

Una revisión de la literatura existente sobre el tema de la potencialidad de la acción colectiva y las redes de movimiento social nos muestra que se trata de un campo de estudio propenso a la interpretación ideológica. La (habitual) condición externa del investigador y su identificación con los sujetos que estudia, suele acarrear una actitud protectora y de idealización de sus prácticas, omitiendo los aspectos que resultan negativos desde la perspectiva de cada autor. Pero, procurando evitar este riesgo, una aproximación teórica a la acción colectiva debe enfrentar el problema de su alcance y potencialidad.

Entendemos por potencialidad la capacidad de los actores para modificar o mantener la situación real de cualquiera de las dimensiones a las que afecta la acción colectiva. Lo que suele ocurrir en la mayoría de las investigaciones es que el análisis de tal potencialidad se encuadra en un modelo dicotómico: izquierda-derecha, beneficios-pérdidas, éxito-fracaso, bueno-malo. No menos frecuente es que el cambio se circunscriba teóricamente al ámbito de lo político y que se suponga que la toma del poder político es condición imprescindible para realizar cambios profundos en el sistema.

Las páginas precedentes nos dan las pistas básicas para discurrir de otro modo. En primer lugar, como señala Touraine y, en general, los teóricos de los nuevos movimientos sociales, el poder no se encuentra únicamente en las esfera del Estado o de la producción ${ }^{4}$. Hoy el poder como dominio-subordinación se extiende a todas las áreas de las relaciones sociales, desde la familia hasta el ejército o el control de la información.

Además, siguiendo a Ibáñez (Prólogo a Mafessoli, 1991), la conducta o posición frente a los dictados del poder no se reduce a un binomio. Caben varias conductas, unas refuerzan el poder y el funcionamiento de los patrones culturales del sistema dominante, otras cuestionan sus fundamentos. Entre las primeras hay dos posibilidades, una que acepta y responde afirmativamente a los dictados del poder (la adhesión al sistema); otra que los rechaza para imponer unos distintos que siguen la misma lógica (la lucha contra una alienación con medios alienados). Se trata, respectivamente, de respuestas directas o inversas al dictado, pero aceptando los principios de funcionamiento. Entre las segundas (las que cuestionan los fundamentos del sistema), caben también dos conductas: una, la de duplicidad, que no se adhiere ni ataca frontalmente al poder, sino que practica la astucia y el rodeo, la versatilidad; y otra que rechaza al sistema cuestionando sus fundamentos, pero sin pretender sustituirlo por otro, se sitúa al margen, poniendo de manifiesto la posibilidad de experimentos alternativos.

Por otro lado, en toda acción colectiva se dirime algo más que los intereses y objetivos explícitos. Puesto que la acción colectiva, como hemos dicho, implica diversas dimensiones -sean latentes o manifiestas-, las transformaciones se pueden efectuar en todas ellas. La lucha, por ejemplo, por conseguir equipamientos urbanos en un barrio, puede conllevar un proceso de acción en el que las mujeres que participan inicien un camino liberador del dominio machista, de apertura hacia ámbitos sociales de los que estaban desplazados, de asunción de responsabilidades de dirección comunitaria. Descubrir cuáles son las dimensiones y las correspondientes potencialidades presentes en un proceso determinado de acción colectiva, es

3. La acción colectiva "es prepolítica, porque enraiza en las experiencias de la vida diaria; y metapolítica, porque las fuerzas políticas nunca pueden representarla completamente" (Melucci, 1989: 73).

4. Véase, por ejemplo, las ideas recogidas a este respecto en el capítulo II, cuando se revisan las tesis de Touraine, Melucci y Offe. 
una responsabilidad de cada investigador, y para ello es conveniente adoptar la propuesta de Hugo Zemelman: “(...) el significado de los contenidos no puede circunscribirse a una estructura teórica, ya que ésta tenderá a considerar sólo a los contenidos que puedan denotar universos de observación ya previstos por ella" (Zemelman, 1987: 98). Esta máxima y los postulados teóricos que hemos expuesto nos guiaron en el estudio de casos cuyos resultados sintetizamos a continuación.

\section{LA ACCIÓN COLECTIVA EN BOGOTÁ Y CARACAS}

\section{Diversidad de objetivos}

Ya que se tiende a olvidar con excesiva frecuencia, conviene recalcar una idea que acabamos de indicar: el sentido de la acción colectiva no se agota en sus objetivos, sean éstos explícitos o latentes. Los objetivos de una organización o de una acción colectiva se encuadran en visiones del mundo, en valores y patrones sociales que constituyen el verdadero sentido de la acción. No obstante, aun siendo insuficientes para la comprensión de las conductas y sentidos de la acción colectiva, tanto los objetivos manifiestos como los latentes son uno de sus indicadores básicos. Pero, a este respecto, frente al énfasis habitual de que las acciones de las organizaciones de base territorial se concentran en reivindicaciones de consumo urbano, hay que subrayar que en el caso de Bogotá y Caracas el fenómeno asociativo recoge una amplia variedad de asociaciones y colectivos, cada uno de los cuales persigue diversos objetivos. Actúan grupos deportivos, culturales, religiosos, ONGs e, incluso, las propias asociaciones de vecinos, que se integran en redes asociativas cuyos objetivos se enmarcan en un desarrollo humano multidimensional (relaciones familiares, moralidad, convivencia, integración comunitaria, formación técnica, lucha contra la delincuencia, ocio y entretenimiento) $)^{5}$.

Por otra parte, se constata la formulación de objetivos diferentes en función de que los conjuntos de acción sean locales o supralocales. En los primeros, la problemática y los objetivos se circunscriben a asuntos de la vida cotidiana y, por lo general, se plantean para el presente o para un futuro inmediato. En los conjuntos de acción supralocales los objetivos pueden vincularse también con cuestiones cotidianas y locales, pero, en los pocos casos que así ocurre, lo local se comprende desde una perspectiva de generalidad. No importa tanto lo concreto y cotidiano en sí como su significado y potencialidad en el contexto global en que se inscribe. La primacía dada a lo político, la programación, la elaboración de proyectos, la institucionalización, el movimiento social y público, dan cuenta de un posicionamiento abstracto y distante que se asemeja más al paradigma político-económico que al estético-religioso característico de los conjuntos de acción locales.

Se comprueba, en definitiva, un cambio del vector principal que articula a las redes asociativas locales y a las extralocales. De la convivencia y la emoción compartida, de lo familiar y cotidiano propio de los conjuntos de acción locales, se pasa a lo racional y abstracto, a la ideología y el proyecto de los conjuntos de acción supralocales. En un caso la percepción de la problemática vecinal se circunscribe al ámbito puramente comunitario y los objetivos se inscriben en las coordenadas de la socialidad, en el otro se transciende ese ámbito y se elaboran proyectos políticoideológicos que implican la toma en consideración del conjunto del sistema.

En consecuencia, más que desempeñar una representatividad pública de los intereses de las asociaciones locales, lo que hacen las organizaciones supralocales y las federaciones de asociaciones en Bogotá y Caracas es reformular y transformar con otros códigos los objetivos perseguidos por aquellas, en las cuales tienen su origen. Se produce así una tensión dinámica, un "feed-back" entre los objetivos y medios de la acción colectiva desarrollada por los conjuntos de acción locales y los conjuntos de acción que incluyen organizaciones supralocales. Una tensión condicionada por los medios de comunicación, que consiguen multiplicar la difusión de las preocupaciones, objetivos y acciones de las redes asociativas, lo que propicia la burocratización y reduce el contacto directo con la base social, pero, al mismo tiempo, contribuye a la autoestima de la red asociativa como conjunto autónomo y acentrado.

En cualquier caso, el componente emocional de las redes sociales y asociativas condiciona la formación de los conjuntos de acción y el sentido de la acción colectiva. La participación, las relaciones en la red asociativa, la decisión sobre los fines a conseguir, implican, al mismo tiempo y de forma indisociable, un componente de racionalidad instrumental y otro de identificación colectiva. En todos los casos, incluso en las asociaciones más clientelistas e instrumentales, la participación misma, el compartir y sentir común, constituyen un objetivo esencial de la acción colectiva.

\section{Conductas y sentidos implícitos}

Recordemos que la interpretación de las conductas y sentidos subyacentes a los conjuntos de acción implica el análisis de las diversas dimensiones presentes en ellos y una perspectiva abierta, no restringida al enfoque habitual de tipo político e instrumental. Importa tanto la dimensión instrumental como la expresiva, y el estilo y los efectos no buscados como los programas y proyectos proclamados. Ahora bien, esto no significa omitir la reflexión sobre su significado estrictamente "político", sino integrarlo como una dimensión de la acción colectiva que se inscribe en valores y patrones de organización y funcionamiento social ${ }^{6}$.

5. El ejemplo paradigmático lo constituyen las comunidades católicas de base: "Una comunidad [católica o eclesial de base] no es un grupo especializado, con un campo de intereses y de praxis reducido. Sus relaciones internas impregnan y se interesan por todas las áreas más significativas de la vida de sus miembros: lo familiar y lo social, lo religioso y lo político, las carencias y las necesidades, lo lúdico y lo festivo" (Centro Gumilla, 1987).

6. Entrecomillamos este término porque coincidimos con Offe (1985) y con Villasante (1991) en que, como proponen los nuevos movimientos sociales, cabe una comprensión de lo político que no se restringe al gobierno y a lo institucional. 
Desde este enfoque, cabe señalar que la acción colectiva en los barrios de Caracas y Bogotá surge para dar respuesta a diferentes necesidades que nunca son totalmente objetivas. La definición de las necesidades obedece a percepciones subjetivas que vienen condicionadas por los parámetros culturales de las redes sociales respecto a qué y en qué medida algo es necesario y cómo se puede conseguir. Y en este contexto, se constata que los pobladores de los barrios diferencian entre necesidades cuya solución depende de la iniciativa y habilidad individual -siempre inscrita en redes sociales- $y$ aquellas otras en que la acción individual no es eficaz y, si lo es, afecta a los restantes vecinos y requiere una actuación colectiva.

Entre las primeras destacan las necesidades materiales de subsistencia, siendo en el plano doméstico de la reproducción donde se concentran las estrategias de resistencia ante la crisis económica que afecta a Venezuela y Colombia. La importancia que se otorga a las redes sociales y la educación como mecanismos de solución a los problemas de subsistencia y como vía de movilidad ascendente en el sistema social, viene a mostrar el valor concedido a la acción individual y privada como medio de ascenso social individual y familiar.

En el plano de la acción colectiva, las iniciativas más numerosas y visibles parten de carencias en el consumo colectivo de los barrios. La organización mayoritaria (asociaciones de vecinos) y la acción colectiva local orientadas a la solución de tales carencias, toman, por lo general, formas clientelistas, que se adaptan a las condiciones políticas y económicas dominantes y a las redes sociales que activan la vida cotidiana. En ello, como señala Castells (1981), tienen una influencia fundamental los partidos políticos, que utilizan el poder del Estado y la propia organización partidista para tratar de controlar las organizaciones barriales a cambio del reparto y manejo de los servicios urbanos.

Además del funcionamiento institucional clientelista, la tradición autoritaria y corporativa promueven un liderazgo caudillista que atraviesa el sistema político y las asociaciones vecinales. En consecuencia, en los barrios consolidados de los sectores populares -en especial en Bogotá, donde se hallan más acentuados los rasgos anteriores-, la dinámica organizativa de las asociaciones de vecinos tiene, en general, un carácter burocrático y piramidal, marcada por la dependencia del paternalismo y el clientelismo político. Una dinámica que, en definitiva, se enmarca en el modelo global de dominación y en los valores culturales predominantes en las redes de relaciones de la vida cotidiana.

La percepción y solución de las necesidades colectivas no se plantea, por tanto, en términos ideológicos de un proyecto de cambio revolucionario. Los pobladores en situación de marginalidad urbana no imputan la responsabilidad de su situación a la estructura de clases (Portes y Walton, 1976), ni elaboran una ideología que se refleje en programas u organizaciones políticas acordes con ella (Touraine, 1989). Se puede culpabilizar al Gobierno, a la corrupción de las élites dirigentes, a la aplicación de políticas incorrectas, pero no se cuestiona la estructura de clases ni el sistema político.
Así pues, la conducta política expresada en la mayoría de los conjuntos de acción locales de los barrios de estratos bajos está orientada por la adaptación racional a las circunstancias del sistema de dominación y por la adecuación a la dinámica afectiva de las redes de relaciones. Pero esta conducta no es tan simple como pudiera parecer, no implica un sometimiento incondicional al poder. Por debajo del comportamiento político adaptativo se descubre una actitud de ambigüedad, de astucia, que se relaciona con una identificación colectiva primordial y con una conducta de fondo reversiva.

Se podría argumentar que la acción de los agentes del poder, orientada a la dominación y legitimación mediante el manejo partidista del Estado y la donación arbitraria de los recursos, ha provocado la emergencia de una conducta política mezcla de excepticismo, cinismo e impotencia, por un lado, y de retraimiento al ámbito comunitario, a la convivencia y la ayuda mutua, con desprecio a los políticos y la política profesional, por otro. La acción colectiva evidencia una desconfianza radical hacia los partidos políticos, tanto los tradicionales y detentadores del poder, como los más recientes y de tendencia ideológica de izquierdas. Como reacción frente a la falsedad del político se desarrolla la conducta reversa -aparenta decir sí a los dictados del poder, pero se opone a él y aprovecha su funcionamientoligada al sentir de la vida comunitaria.

Pero, aun siendo un campo de actuación principal, los sentidos del proceso de la acción colectiva no se circunscriben al consumo urbano ni a su dimensión política entendida como opinión y acción frente al gobierno del Estado. Existen, como señala Evers (1985), diversas formas de dominación que no pueden reducirse a la delimitación tradicional del campo de la política ni a los antagonismos de clase y, tomando en cuenta este enfoque, incluso en las organizaciones vecinales más clientelistas y, sobre todo, en las de tipo sociocultural y autónomas de los Partidos, las prácticas del accionar colectivo ponen en juego múltiples valores, conductas y sentidos que afectan a las diversas formas de dominación.

Las organizaciones y conjuntos de acción desarrollan sus prácticas en un campo social que redefine el campo político y lo sobrepasa: la ética, las relaciones de género, la autogestión solidaria, las formas de organización y participación. La acción colectiva se constituye en fuente experimental de una nueva normatividad y de nuevas creencias sobre la emancipación de la mujer, los valores éticos, la identificación social, la corrupción. De este modo, como observan los estudios de los nuevos movimientos sociales, también la acción colectiva de base territorial en Bogotá y Caracas se convierte en acción prepolítica o metapolítica, en la que se inventan prácticas y surgen identificaciones nuevas.

Determinadas organizaciones y redes de acción colectiva experimentan, por ejemplo, modos de actuación democrática real, en contraste con el contexto políticopartidista, marcado por modos autoritarios aunque formalmente democráticos. No se trata, por supuesto, de modelos de actuación democrática puros o ideales, pues las costumbres autoritarias están también presentes en la 
vida cotidiana de los barrios, pero se ensayan acciones colectivas que cuestionan los patrones que rigen las relaciones personales, la organización y toma de decisiones, la asunción de responsabilidades en la gestión de los problemas colectivos.

La conducta transformadora en esas dimensiones se vincula fundamentalmente con los conjuntos de acción donde son débiles las relaciones que mantienen la base social y las organizaciones locales respecto al poder. Su expresión concreta en los conjuntos de acción formados con las comunidades católicas de base, los colectivos culturales de los estratos bajos, las asociaciones de vecinos no partidizadas y los grupos resultantes de la acción de ONGs, desarrollan prácticas cotidianas de participación y acción que se sitúan más allá o al margen de los patrones culturales dominantes en ambas ciudades.

En estos casos la acción colectiva enfatiza lo social, plantea cuestiones de identificación personal y colectiva, afecta a la interpretación de las normas sociales y políticas, las reformula y crea orientaciones alternativas. La acción colectiva urbana autónoma de los partidos políticos redefine el espacio de la ciudadanía, en su pleno sentido, económico, cultural, social y político. En este proceso, se siguen conductas que cuestionan la lógica del sistema, se revaloriza la dimensión afectiva y comunitaria de las relaciones ciudadanas, los lazos interpersonales, la solidaridad, el igualitarismo, la democracia participativa, que se contraponen a los valores vigentes del sistema: competitividad, individualismo, autoritarismo, clientelismo, paternalismo del poder. Además, los participantes incorporan un componente de realización personal que se expresa en el compromiso con la organización y la acción, y en la importancia de los cambios de valores y conductas personales.

En cualquier caso, la acción colectiva utiliza como vehículo habitual la organización comunitaria local y no la formación de una red asociativa unificada a nivel general. Un hecho que resulta revelador del sentido de identificación comunitaria ligada a la homogeneidad social y la delimitación espacial que orientan a las organizaciones y conjuntos de acción. Pero la heterogeneidad, fragmentación y localismo asociativo no tienen por qué interpretarse a priori como un rasgo negativo de la organización y acción colectiva en los barrios. La diversidad de organizaciones da cuenta de una multiplicidad de principios de identificación y una dinámica de la acción colectiva rica en contenidos y alternativas de sentidos. Es esa misma diversidad de organizaciones y conjuntos de acción la que enriquece la vida cotidiana en los barrios de las ciudades y la que impide encajonar en un solo proyecto, en un solo modelo, los principios de funcionamiento social.

\section{Potencialidades de la acción colectiva en las ciudades latinoamericanas}

Que las prácticas colectivas tengan algún sentido no garantiza que dispongan de capacidad para viabilizarlas, para generar y ejercer una influencia que haga realidad los sentidos de la acción. Ahora bien, la potencialidad de la acción colectiva no se puede medir únicamente por su éxito o fracaso inmediatos, ya que sus efectos tienen también una proyección histórica. Es más, incluso la noción de éxito es equívoca, pues depende de los parámetros que se usan para medirlo y de quiénes los manejan.

Dando esto por sentado, debemos señalar que en los barrios consolidados de Caracas y Bogotá (de modo extremo en los sectores de estratos medios y altos), el número de personas que participan en organizaciones y acciones colectivas es bastante reducido y, por consiguiente, poco relevante estadísticamente. Sin embargo, su repercusión pública es mucho mayor en razón de las movilizaciones que realizan y del eco que provocan a través de los medios de comunicación -en especial en Caracas-. Por otro lado, su importancia cualitativa resulta también mayor en función del significado social, cultural y político que presentan en su praxis los conjuntos de acción.

Los índices más altos de participación se dan en los inicios de los barrios de invasión y, en ellos, un resultado inmediato de tipo instrumental de la acción colectiva se refiere a la lucha por la propiedad de suelo para levantar la vivienda y por la dotación de infraestructura y equipamientos colectivos: electricidad, acueducto, alcantarillado, asfaltado, centros de salud y educación, transporte. En este campo, sea por autogestión colectiva de los vecinos sea por la presión y negociación con los propietarios del terreno y la Administración Pública, o por la (generalizada) combinación de estas modalidades, es evidente la eficacia de la acción colectiva y no vamos a insistir en ello, pues ya lo han destacado otros investigadores.

Vinculado al proceso de consecución de esos objetivos de tipo material, la acción colectiva en los inicios de los barrios de invasión cumple una labor de integración social y de identificación colectiva. Una función fundamental en ciudades como Caracas y Bogotá, que han crecido de manera espectacular por las grandes corrientes migratorias de población rural, con todo lo que ello acarrea de desarraigo y dificultad de adaptación al medio urbano de las metrópolis latinoamericanas. Pero el proceso de identificación colectiva en el nuevo medio urbano no acaba en los inicios de los barrios de invasión, sino que va regenerandose en la acción colectiva desarrollada por los diversos conjuntos de acción una vez consolidado el asentamiento. Aunque la inmensa mayoría sólo participe de modo puntual en determinadas acciones, la población de los barrios populares encuentra en la acción colectiva un espacio y un referente de identificación básico. Es cierto que esta identificación como pueblo capaz de actuar y modificar su situación es bastante imprecisa y ambigua, pero tal vez en ello mismo guarde su fuerza de resistencia y superación de unas condiciones económicas y políticas excluyentes y adversas.

La potencialidad de la organización y la acción colectiva consiste también en ser campos de experiencias grupales que contradicen algunos valores dominantes en el ámbito privado y en el público. La mayor incidencia, en este sentido, tiene que ver con la participación de la mujer, que está conllevando un cambio significativo en los roles atribuidos a su género, de modo que el campo de desarrollo personal se está abriendo fuera del hogar, asumiendo 
responsabilidades sociales a las que antes era ajena. La organización y la acción colectiva con participación de la mujer, en cuanto que es una forma más de socialización -fundamental en los barrios populares- resquebraja la educación patriarcal y machista característica del hogar, abriendo y ampliando los horizontes personales y grupales.

Del mismo modo, esta participación femenina modifica los valores que orientan la forma de organización y los contenidos de las luchas y reivindicaciones. Los valores que se han adscrito tradicionalmente a la mujer: defensa de la vida y la convivencia por encima de la ideología, apego a lo concreto y cotidiano, el componente emocional sobre el puramente racional, la relación horizontal y comprensiva, están transformando los horizontes de la acción colectiva de base territorial. El carácter instrumental de las asociaciones pasa a asumir un contenido afectivo, de convivencia, cotidianeidad y moralidad que incide en los objetivos y formas de la acción.

La participación en particular de mujeres jóvenes repercute, también, en un cambio de valores y expectativas sobre su futuro como madres, esposas y trabajadoras. Contribuye, por ejemplo, a enfrentar y modificar su posición tradicional sobre algunos problemas muy comunes en los sectores populares: embarazos no deseados, matrimonios prematuros, autoestima frente al varón, educación para las responsabilidades en el hogar, formación técnica para el trabajo, etc. Cuestiones que los intelectuales tienden a olvidar o relegar a un segundo plano en razón de una preponderante -a veces exclusiva- perspectiva político/económica, pero no por ello carentes de interés vital y analítico.

Respecto a los jóvenes varones, frente a la frustración por la imposibilidad de incorporarse al mercado laboral en unas condiciones dignas, la organización y acción colectiva que dirigen o en la que participan, actúa sin duda como freno a la marginalidad social y la delincuencia. En efecto, en ciudades como Caracas y, sobre todo, Bogotá, donde la violencia y los grupos de delincuentes juveniles alcanzan índices relativos muy altos, la preocupación no sólo por la educación reglada sino por la formación integral de los niños y jóvenes es prioritaria en los sectores populares. Por ello, practicamente todas las organizaciones desarrollan acción colectiva con fines educativos y de integración juvenil, contribuyendo de forma eficaz -aunque sus resultados sean difícilmente cuantificables- a reducir los problemas de marginalidad y delincuencia.

La diversidad asociativa que hemos venido destacando es, pues, el ejercicio de distintas iniciativas que ensayan y aportan sus propios valores y soluciones a una variada gama de problemas. Algunos de estos valores, como la solidaridad, la igualdad, la responsabilidad en los asuntos colectivos, que defienden y practican algunas asociaciones de vecinos y, de manera especial, las religiosas, culturales y ONGs, no tienen una potencialidad perceptible facilmente. Pero, en cualquier caso, tienen la fuerza de mantenerse como contrapeso a otros valores predominantes en la esfera pública y privada: competitividad, egoísmo, corrupción.

En algunos casos la potencialidad se vincula con la forma misma de la organización y la acción colectiva.
Quiere esto decir que un mensaje importante de los colectivos culturales, religiosos, deportivos y de ciertas asociaciones de vecinos, es su propio funcionamiento. Las prácticas de organización y acción democráticas, el respeto y colaboración con otros grupos, la transparencia en la gestión de los recursos comunes, no sólo son un objetivo esencial de una parte de las asociaciones, sino que educan y ejercen un efecto público a medio y largo plazo.

Por último, centrándonos en el nivel político clásico, la organización y acción colectiva, entre otros factores, han actuado como impulsores de la implantación de la elección directa de representantes municipales y de los recientes procesos de descentralización administrativa que tienen lugar en Colombia y Venezuela. Por supuesto, estos procesos no implican por sí solos un cambio de fondo en el funcionamiento del sistema político, y menos aún si -como ocurre hasta el momento- no se transfieren recursos y capacidad fiscal acordes con la nueva situación. Podría ser; incluso, que la finalidad de la descentralización consista en recuperar la legitimidad erosionada de los partidos y el sistema político en general. Pero, como quiera que sea, revela la importancia creciente de lo local así como la necesidad de acercar la Administración Pública al ciudadano, y en ello han jugado un papel principal las organizaciones y la acción colectiva de base territorial.

En todo caso, y habiendo señalado los efectos anteriores, coincidimos con la mayoría de los investigadores en que el rol de las organizaciones locales de los sectores populares de Caracas y Bogotá es bastante limitado desde el punto de vista de la transformación política del sistema ${ }^{7}$. Es más significativo, por el contrario, como fuente de reclutamiento y cooptación de los Partidos y como apoyo a un sistema político de funcionamiento clientelista. No obstante, como hemos argumentado en el apartado anterior, esta conclusión es excesivamente simplista, pues la conducta subyacente es mucho más compleja de lo que pudiera parecer a primera vista.

Pero no vamos a reincidir en la interpretación de esa conducta, pues debe haber quedado clara en apartados anteriores. No limitaremos a señalar que, desde el análisis realizado en esta investigación, las razones de la incapacidad organizativa de los sectores populares para acometer una transformación del sistema de dominación política se debe a varios factores. Por un lado estaría la dimensión afectiva, básica en la identificación colectiva de las organizaciones en los barrios, que se convierte en una debilidad fundamental de las organizaciones de base territorial para actuar de forma unificada. Esta debilidad se asocia a la preponderancia de la identificación colectiva localista, que no traspasa el ámbito de lo comunitario, dificultando la conexión y coordinación con organizaciones de otros barrios y, más aún, de otros estratos sociales. Una limitación que tiene ver, también, con la disparidad del discurso de las organizaciones locales, de tipo afectivo, cotidiano, y el de los dirigentes de las organizaciones supralocales, de tipo racional, abstracto.

7. Véase, por ejemplo, Portes y Walton (1976), Roberts (1978), Castells $(1981,1986)$ y Hurtado (1991). 
Va ligada, también, a las limitaciones derivadas de la falta de coordinación de las organizaciones barriales para dar respuesta a situaciones que se integran en condicionantes estructurales globales. Pero el problema de fondo es que los sectores populares sienten que no hay posibilidad de transpasar los condicionantes estructurales derivados del modo de desarrollo dependiente. La estrategia consiste en adaptarse a ellos de modo que se obtengan los máximos beneficios posibles, pero sin provocar luchas frontales. Con ello se facilita la intervención de agentes e Instituciones externas, que tratan de organizar a los vecinos según sus propios criterios e intereses, siendo excepcionales -aunque cada vez más numerosos- los casos en que se produce participación activa y decisoria de los destinatarios de los proyectos propuestos por las organizaciones religiosas y las ONGs.

Pero la influencia de los agentes externos se ha de comprender en el marco de un contexto político -una estructura de poder-que no sólo no incentiva sino que se orienta a eliminar la lucha política que pretenda cambiar el sistema. Los actores fundamentales que desempeñan esa labor son las élites de los partidos políticos tradicionales, que a través del poder que les otorga la patrimonialización del Estado y con mecanismos clientelistas, aprovechan la precariedad y las redes sociales de los estratos bajos para debilitar su capacidad de organización autónoma y unificada. Y, cuando los recursos del Estado no son suficientes para llevar a cabo esa función, se recurre a la represión violenta de las demandas y la organización política independiente.

\section{BIBLIOGRAFÍA}

Castells, Manuel (1981): Capital Multinacional, Estados Nacionales y Comunidades Locales. Siglo XXI, México.

Centro Gumilla (J. M. Munárriz, P. Trigo y A. Sosa) (1987): "Comunidades eclesiales de base en Venezuela", en Gómez CALCAÑo, Luis (Comp.) (1987): Crisis y movimientos sociales en Venezuela. Tropykos, Caracas.

COHEN, Jean (1985): "Strategy or identity: new theoretical paradigms and contemporary social movements". Social Research, vol. 52, no. 4: 663-716.
Evers, T. y otros (1983): Movimientos barriales y Estado. CINEP, Bogotá.

EvERS, Tilman (1985): "Identity: the hidden side of new social movements in Latin America", en Slater, D.: New social movements and state in Latin America. CEDLA, Amsterdam.

FERNÁNDEZ, Beatriz (1992): "Entre la solidaridad informal y la debilidad formal", en Cariola, Cecilia (ed): Sobrevivir en la pobreza: el fin de una ilusion. Cendes/Nueva Sociedad, Caracas.

GARRIDO GARCÍA, F. J. y RAMOS, M. (1994): "Tejido social y organización comunitaria en Caracas", en VILLASANTE, Tomás R. (Ed.) (1994): Las ciudades hablan. Nueva Sociedad, Caracas.

Hurtado SalazAR, S. (1991): Dinámicas comunales y procesos de articulacion social. Las organizaciones populares. Tropykos, Caracas.

LÓPEZ, Angela (1994) "La organización popular en Lima: de la tradición comunitaria a la participación ciudadana”, en Villasante, Tomás R., (Ed.) (1994): Las ciudades bablan. Nueva Sociedad, Caracas.

MAFFESOLI, M. El tiempo de las tribus. Icaria, Barcelona.

MeLuCCI, Alberto (1989): Nomads of the present. Hutchinson Radius, Londres.

OfFe, Claus (1992): Partidos políticos y nuevos movimientos sociales. Sistema, Madrid.

PORTES, A. y WaLTON, J. (1976): Urban Latin America: the political condition from above and below. University of Texas, Austin.

ROBERTS, Brian R. (1978): Cities of peasants. Edward Arnold, Londres.

SCHERER-WARREN, Ilse (1993): Redes de movimentos sociais. Loyola, Sao Paulo.

Touraine, Alain (1978): Las sociedades dependientes: Ensayos sobre América Latina". Siglo XXI, México.

Touraine, Alain (1989): América Latina. Política y sociedad. Espasa-Calpe, Madrid.

Villasante, Tomás R. (1991): Movimientos ciudadanos e iniciativas populares. HOAC, Madrid.

Villasante, Tomás R., (Ed.) (1994): Las ciudades bablan. Nueva Sociedad, Caracas.

Zemelman, Hugo (1987): Conocimiento y sujetos sociales. Colegio de MéxicoMéxico.

\section{RESUMEN}

Uno de los problemas principales en las grandes ciudades latinoamericanas lo constituye la integración, organización y acción colectiva de los nuevos residentes urbanos. Pero el estudio de estos temas requiere cambiar las aproximaciones teóricas tradicionales sobre movimientos sociales urbanos. En este sentido, el autor propone una perspectiva original y la contrasta en el estudio de casos de Bogotá y Caracas.

\section{ABSTRACT}

One of the main problems of latin american cities are integration, organization and collective action of new urban residents. Nevertheless, analysis of this issue requires a change of traditional approach about urban social movements. The author proposes an original perspective and contrast it with Bogotá and Caracas as study cases. 